Ploetner, C., Telford, M., Braekkan, K., Mullen, K., Turnbull, S., Gumley, A. and Allan, S. (2020) Understanding and improving the experience of claiming social security for mental health problems in the west of Scotland: a participatory social welfare study. Journal of Community Psychology, 48(3), pp. 675-692.

This is the peer reviewed version of the following article, Ploetner, C., Telford, M., Braekkan, K., Mullen, K., Turnbull, S., Gumley, A. and Allan, S. (2020) Understanding and improving the experience of claiming social security for mental health problems in the west of Scotland: a participatory social welfare study. Journal of Community Psychology, 48(3), pp. 675-692, which has been published in final form at http://dx.doi.org/10.1002/jcop.22278

This article may be used for non-commercial purposes in accordance with Wiley Terms and Conditions for Self-Archiving.

http://eprints.gla.ac.uk/202087/

Deposited on: 31 October 2019

Enlighten - Research publications by members of the University of Glasgow http://eprints.gla.ac.uk 
Understanding and Improving the Experience of Claiming Social Security for Mental Health Problems in the West of Scotland: A Participatory Social Welfare Study

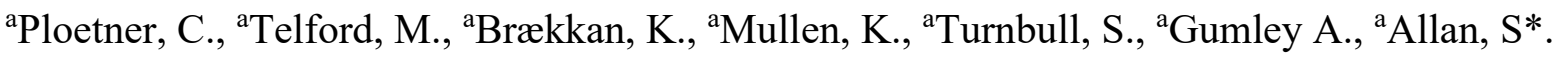

${ }^{a}$ Glasgow Institute of Health and Wellbeing, University of Glasgow

Glasgow Mental Health Research Facility*

Glasgow Institute of Health and Wellbeing

University of Glasgow

Fleming Pavilion

West of Scotland Science Park (Todd Campus)

Glasgow, G20 0XA

Email: $\quad$ Stephanie.Allan@glasgow.ac.uk

Phone:

\section{Acknowledgements}

We wish to thank all of our participants, The Carers and Users of Services in Clinical Psychology Training Group (CUSP), Mental Health Network (Greater Glasgow) and ACUMEN. Additionally, we wish to thank Maddie Blanche for their critique of this manuscript.

\section{Disclosure Statement}

The authors report no declarations of interest.

\section{Ethical Approval}


The study received ethical approval from University of Glasgow (200160083). Travel expense reimbursement was offered to every participant and was an explicit part of the ethics application process. 


\title{
Understanding and Improving the Experience of Claiming Social Security for Mental Health Problems in the West of Scotland: A Participatory Social Welfare Study
}

\begin{abstract}
Aims: A growing body of literature links claimant interactions with the UK social security system and negative psychological consequences. Psychologists for Social Change developed a framework to outline proposed mechanisms of psychological impact from austerity.
\end{abstract}

Methods: This co-designed study aimed to make informed comment on areas of dis(agreement) between the Austerity Ailments framework and how people claiming for mental health problems describe their own experiences. In line with the participatory social welfare design of the study, qualitative analysis was performed by both claimants and academics.

Results: The overall findings indicate that existing framework mostly captured claimant experiences. However, some aspects of the claimant experience (particularly social aspects) were not well captured.

Conclusion: Claimants were keen to utilise this study as an opportunity to gather claimant ideas on how to improve the system. Therefore, we report their suggestions which may be useful for those designing and improving social welfare systems

Keywords: Mental Health, Social Security, Community-Based Participatory Research, Psychology, United Kingdom

\section{Introduction}


Since 2008, successive UK governments have implemented a programme of austerity which has disproportionately affected those on low incomes, for example, people claiming benefits for a mental health problem (McGrath, Griffin, \& Mundy, 2015). Following welfare reform, the most substantial losses in funding are apparent in the most disadvantaged communities of the UK (Cummins, 2018). An increase in poverty has been particularly noticeable amongst communities situated in former industrial areas such as Scotland (Beatty, Fothergill, \& Houston, 2013). Glasgow, Scotland's largest city, has the largest share of economically deprived areas within Scotland (MacLeod, Curl, \& Kearns, 2019). A recent study suggests that Scotland has a higher rate of people claiming benefits for a mental health problem than other areas of the UK traditionally associated with industrial decline, such as Wales and the North East and North West of England (Viola \& Moncrieff, 2016).

In the UK, benefits are administered by the Department for Work and Pensions (DWP). Since the introduction of the Work Capability Assessment, it has been noted that claimants have experienced increases in self-harm, self-reported symptom severity and psychopharmacological treatment (Barr et al., 2016). Introduced in 2008, the Work Capacity Assessment (WCA) is an example of a change to the social security system (Grover \& Piggott, 2013). While some people are awarded Employment and Support Allowance (ESA) without an assessment, claimants are usually required to attend a WCA (conducted by an independent clinician) to confirm that they are unfit for work. General practitioners report that the WCA is unfit for purpose, stating that it distresses their patients and undermines their evaluation of the claimant's health status (Griffiths \& Patterson, 2014). The system has also changed for non means-tested benefits. Disability Living Allowance (DLA) was replaced by Personal Independence Payment (PIP) in 2013, with qualifying criteria being harsher for the new benefit (Machin, 2017). Like ESA, PIP is usually conditional upon a medical assessment. The format of the PIP assessment differs slightly because the assessment focuses on the extent to which claimants can perform daily activities rather than their capability for work. There is a concern that both tests only assess the ability of a person to perform arbitrary tasks and activities which may bear little relation to the issues for which the person is seeking support (Baumberg, Warren, Garthwaite, \& Bambra, 2015).

Those affected by changes to the UK benefits system may frequently experience feelings of shame and humiliation (Garthwaite, 2014; Harrington, 2012; Samuel, Alkire, Zavaleta, Mills, \& Hammock, 2018). Research findings suggest that exposure to ongoing 
shame and humiliation is central to many forms of emotional distress and increases the risk of depression, especially in individuals who experience social isolation (Kim, Thibodeau, \& Jorgensen, 2011). Community resources aimed at preventing social isolation and loneliness have been reduced, particularly in deprived areas, leaving young families, elderly and disabled people at increased risk of becoming isolated (Hastings et al., 2013). Loneliness and isolation are linked to common psychological difficulties and appear to be linked to increased mortality (Holt-Lunstad, Smith, \& Layton, 2010).

Longstanding psychological theories can be used to understand the ways in which engagement with the social security process for mental health problems can contribute to claimants experiencing distress. For example, the process of claiming disability benefits in the UK is characterised by long periods of waiting, leading to high levels of uncertainty and anxiety (Baumberg, 2014; Cooper \& `Stewart, 2015; Litchfield, 2013). A feeling of powerlessness can further reinforce disability claimants' fears around benefit assessments, decision letters and (if they are not successful) the need to appeal, because claimants feel they are unable to influence the outcome (de Wolfe, 2012; Garthwaite, 2014). Having little autonomy over one's daily life, combined with material insecurities and a loss of hope, can harm an individual's mental and physical health over the course of their life (McGrath et al., 2015).

Psychologists for Social Change have synthesised evidence of the pathways to mental distress associated with austerity into a framework. The austerity ailments framework (McGrath et al., 2015) has a clear strength in its extensive overview of empirical psychological and clinical practice evidence. This provides a conceptualisation of psychologists' understanding of how experiencing austerity may lead to distress. The key domains are Humiliation and Shame, Fear and Distrust, Instability and Insecurity, Isolation and Loneliness, and Being Trapped and Powerless. However, while the austerity ailments framework is based on existing evidence regarding pathways to adverse psychological outcomes, it was not developed by claimants. Consequently, this may not represent how claimants understand their own experiences of claiming benefits. Academic and social policy research has previously been criticised for failing to engage with service user discourses (Beresford \& Carr, 2018). There is therefore a need to understand how service users experiencing austerity policies understand the resulting impact on their own lives. 
Within this study, we aimed to make empirically informed comment on areas of (dis)agreement between what is proposed by the framework and the actual experiences of claimants when discussing mental wellbeing in the context of austerity policies. The present study was developed collaboratively by individuals with lived experience of claiming benefits for a mental health problem and academic researchers.

\section{Method}

\section{Design \& Theoretical Orientation}

Reporting is in line with CORE-Q (Tong, Sainsbury, \& Craig, 2007). In order to develop methods best suited to address our participatory research aims, we designed our study through an iterative co-production process. Co-production recognises service-users as endowed with skills, knowledge and experiences that enable them to contribute to and take leadership in research (Clark, 2015). It also aims towards improving understandings of multiple contextual factors (social, economic and environmental) that perpetuate adverse psychological outcomes (Zlotowitz \& Williams, 2013).

Many projects that involve members of the public give little information on the role of lay researchers and the value of their contributions to research (Staniszewska et al., 2017). The need for research to foreground the experiences of claimants was proposed by a longterm social security claimant who believed claimants were underrepresented in social security research. Through a meeting with an academic, mentoring was agreed to help facilitate the formal design and conduct of the study, including an ethics application. A group of carers and mental health service users are involved in designing and delivering teaching within the University of Glasgow clinical psychology programme. This group agreed to become involved in the project. Several members of this group had links to peer-run groups which provide support to people experiencing mental health problems, which lead to the decision that recruitment should proceed through these networks so that potential participants could be supported. Several meetings took place in which the research question and ethics applications (including the creation of the focus group schedule) were finalised. Critical feedback was a key part of these meetings and engaging with this critical feedback was crucial to the success of this project. The final focus group schedule (Table 1) is an outcome of critical feedback 
and the development of this was a vital part of this study. It reflects what claimants and those who care for them believe to be the essential questions to ask to understand the lived experience of someone claiming social security for a mental health problem. (Beresford \& Carr, 2018)

This study presents empirical research grounded in the expertise of people who have experienced the impact of social security policies. In sum, using a participatory social welfare approach resulted in data relevant to issues that are valued by claimants and not just academic researchers.

\section{Participants}

Participants were required to have claimed social security benefits for a mental health problem. In line with the co-produced nature of the study, participants were recruited within the linked peer-led community organisations. During the design of the study, it was apparent anonymity was a concern due to the potentially stigmatising nature of being a claimant; therefore, we only routinely gathered information on the gender of participants (11 women and 12 men). Participants quotes are reported using pseudonyms.

\section{Data Collection}

All focus groups were held on the premises of local mental health support organisations to ease access and familiarity for participants. After informed consent was taken, the focus groups were facilitated by $\mathrm{CP}, \mathrm{MT}$ and SA following the topic guide, audio-recorded and transcribed verbatim by CP and MT. A total of four focus groups with a total of 23 participants were conducted between March and May 2017.

\section{Analysis}

Framework analysis was carried out by MT in line with the steps delineated by Gale et al. (Gale, Heath, Cameron, Rashid, \& Redwood, 2013). Group analysis of qualitative data provides greater depth and breadth than that of a single person (Belone et al., 2016). Inductive qualitative template analysis (Brooks, McCluskey, Turley, \& King, 2015) was also performed by $\mathrm{CP}$ and an anonymous claimant (who was also involved in designing the study) 
to explore for differences between the existing framework and claimant experiences. As part of the ongoing process of researcher reflexivity, all coders kept memos to capture reflections and ideas as they developed. The final list of themes was agreed by consensus following discussion between the three coders. The terms "social security", "benefits" and "welfare" were used interchangeably by participants within the focus group, reflecting widespread differences in language. This is reflected within the write up of the final report.

\section{Results}

The five key domains of the austerity ailments framework appear to be supported within the narratives of claimant experiences. However, two further key themes were constructed (Support Seeking and Social Stigma), which also appeared relevant to the reality of claimant experiences. The next section will present supporting quotes for the analysis. In the design stage of the study, claimants wanted to ask about suggestions to improve the system. During the design of the study, claimants stated that it was important to use the opportunity to ask people for their thoughts on how they would improve the benefits system. Several of these recommendations of improving the current benefits system to better suit claimants are summarised under Suggestions for Improvement.

\section{Humiliation and Shame}

Within the proposed framework, the domain of Humiliation and Shame refers to the low status assigned to those on low incomes. This is provoked by the growing gap between the rich and the poor, which places a sense of blame on poor people for their own need (Psychologists For Social Change, 2015). Claimants frequently spoke about being dehumanised during the assessment process. In one case, a participant (who was in tears) describes being treated in a degrading manner and feeling as though they were merely a number to the system, rather than a human being.

You know, you're just treated like a number, and a percentage and a whatever... It's just the most degrading, for people who have got mental health challenges, it's just absolutely abysmal, the way you are treated (Bobbie, Focus Group 2) 


\section{Fear and Distrust}

The domain of Fear and Distrust refers to research demonstrating that fear and distrust are linked to the development and maintenance of mental health problems. The domain of Fear and Distrust appeared particularly apparent when participants discussed attending medicals. During interviews they cited fears that their health was misreported and misjudged and perceived this to be because assessors in medicals were merely there to meet targets.

The bottom line is that they've got targets to make, and that's the bottom line. So, if they had to get ten people off of benefits out of a hundred, then those ten people are gonna come off of benefits, you know regardless of how much research you do for this, that and the next thing (Avery, Focus Group 2)

Fears that the wellbeing of claimants was not taken seriously appeared to lead to distrust in the assessment process. Distrust in the process leads to claimants feeling obligated to take specific actions. This is demonstrated in the example below, in which a participant discusses not attending medicals alone in case the medical assessment process deliberately misconstrued this as a sign that they were not deserving.

In fact, knowing that you've got to take somebody else to get through it can be frightening. [Other participants: Mmhmm...] knowing that you can't handle it on your own [Other participants: Yep.] (Nehal, Focus Group 1)

Discussions of experiencing suicidal thoughts and feelings in relation to fear about interacting with the benefits system were common. Many participants were tearful or appeared distressed when discussing how low they felt. In the example below, a participant highlights that the outcome of the process of claiming social security for a mental health problem is uncertain. The participant states that if she were found to be fit for work, she would take her own life with a planned method. Furthermore, this claimant highlights a common concern expressed by claimants - that they could superficially "look fine" to those assessing them.

I became Anorexic and I was going through counselling and I realised... I had been sexually abused from four years old... As everyone is getting called up now, and I look fine now, and to be honest, if I was told to go back to work, I would overdose. I 
would kill myself, because I've went through too much to get myself to where I am this now, and it was a lot of hard work and a lot of heartache... I couldn't go back" (Jamie, Focus Group 2)

\section{Instability and Insecurity}

Within the austerity ailments framework, instability describes experiences at a community level, in particular, a feeling that authorities are unreliable or untrustworthy. Insecurity describes both personal and material insecurity as a consequence of income level (McGrath et al., 2015). Instability and Insecurity were associated with practical concerns with life on benefits. For instance, some participants cited that it was easier to get into debt during manic episodes, which left some with no secure financial recourse. Universal Credit, a newer benefit, was singled out for criticism because it is paid once a month, making budgeting particularly tricky.

It's amazing how quick the debts come, isn't it? How.... see with Bipolar and got Universal Credit and get paid once a month, you can spend that in one day [Agreement from other participants]. See when you are Bipolar-Manic, they wouldn't last you until dinner time” (Frankie, Focus Group 1)

During the research process, many claimants were transferring from DLA to PIP. Conversations such as the example below were common, where a participant highlights that their transfer onto PIP resulted in them temporarily being without benefits, which placed them in financial insecurity because their bills could not wait.

Yeah, because my DLA runs out next month. So I've only got that up until the beginning of May. So I've really just got three weeks left before the DLA is finished. And I thought the PIP would take over from it. [Robin: But it is backdated.] Backdated doesn't really help me, because it doesn't pay my rent. You can't just tell your landlord, "Sorry, but you just need to wait." (Dali, Focus Group 3)

Benefit reassessments also carry the risk of a reduction in financial income. Having benefits cut in this manner was highlighted as being a source of mental distress. As described by the participant in this example, people claiming social security for a mental health problem are 
already unwell. The financial loss incurred can result in a vicious circle, resulting in people becoming more unwell.

\begin{abstract}
And having a mental health problem, it's another kinda thing...having thoughts of catastrophizing things and having the benefit cut. That's less money you got to live on. So it's easy to fall into that kinda vicious circle if your mental health isn't particularly great. And assist with your everyday suffering kinda thing (Ash, Focus Group 1)
\end{abstract}

Notably, even people such as Frankie, who reported a positive experience in claiming social security (indicated by them being successful in their claim) still reported a sense of insecurity while they were waiting for the decision, which was detrimental to their wellbeing.

You take it to bed with you and when you get up, it's still there. And you will never get better in that environment. (Frankie, Focus Group 1)

\title{
Isolation and Loneliness
}

The existing framework defines Isolation and Loneliness as both the social and cultural concern underlining reduced resources supporting community living, social support and contact for groups at risk of being lonely and isolated. Participants noted that the impact of financial insecurity and of being on benefits had increased their likelihood of social isolation. Frequently, participant discussions appeared linked to concepts of social status and identity, wherein participants described being unable to fully participate in society because of poverty.

It stops you from being part of society, because you can't do what you want to do.... You can't go out for a night out and not worry about what you are spending. When you are working, you can go out once a month and you can really let loose. You can't do that when you are on benefits.... So you feel like you've lost a bit of your social... status (Nehal, Focus Group 1)

However, the reasons for feeling unable to participate in society were described as going beyond poverty. For example, becoming isolated because other people would no longer talk to them. Claimants also described feeling rejected by those who are in work. In the example 
below, the participant invokes the concept of feeling as if they are a different class to other people because they are claiming benefits for a mental health problem. While rejection from others may be rooted in public stigma, it appeared to result in social isolation.

My opinion is that it makes you another class. You got upper class, working class and then you're disabled. It is like another class altogether. And even some of the working folk wouldn't talk to me, because, no, because you aren't getting up in the morning and going to work. It is like being another class situation altogether (Robin, Focus Group 3)

Aside from feeling rejected by society at large, some participants expressed that being on benefits had, in some cases, led them to experience rejection from those closest to them, such as their family.

You can get isolated from family when you have a mental health problem and physical problems as it's too much for them sometimes... my family have a high work ethic sorta thing, so they don't like me being on benefits... but what about if I get ill? If I get ill and get an episode then it's difficult for me to stand on my own two feet, I have to get support (Micah, Focus Group 4)

\section{Powerlessness and Being Trapped}

Finally, being trapped and powerlessness encompass the removal of choices from the lives of many people who struggle on low incomes. Central experiences of entrapment are a loss of hope in the possibility of being able to change life circumstances, and result in an individual feeling powerless (McGrath et al., 2015). Participants stated that being a social security claimant for a mental health problem prevented their full participation within society, compared to those who are in work. In the example below, a participant commented that certain aspects of their life had become "frozen" and they feel trapped within the system.

I feel...in fact, I feel as if my life stops when I am on benefits. When I am working, I feel as if I am getting on in life. I feel as if my life stops or at least, certain sections of my life stop...I went to University, I should, I should be doing these things, but it's 
not really happened for me, so I feel like my life, in some respect, has frozen (Nehal, Focus Group 1)

Participants also described the social security system itself as contributing to a feeling of powerlessness. The participant in this example describes having no control when their benefits were suddenly stopped, leaving them with reduced income.

It's been so long since I first applied... but I did have a situation a couple of years ago, which was so stressful. Out of the blue my benefits just stopped... (Avery, Focus Group 2).

Claimants also described being spoken to as if they were unreliable and untrustworthy narrators. Being viewed as unreliable by the system seemed to resonate with the majority of participants, with many expressing a clear sense of frustration and powerlessness.

I phoned up and said that something has happened here, my benefits have stopped, and... I said "Well, I didn't get any letter" and he says, "Well, you'll have to speak to your postman"...I mean, to come out with things like "You'll have to speak to your postman", you just want to say, "I'm not in Primary One" [Bobbie: you don't want to be spoken down to]. So that was the bad experience... this whole call system where there's no continuity... [Group murmurs in agreement] that went on for five months, and at the end of it, it was an error on their part (Avery, Focus Group 2)

The next section will introduce a discussion of further themes which emerged from inductive analysis that did not fit directly into the existing framework described by Psychologists For Social Change (McGrath et al., 2015). This analysis helps further develop an understanding of the experience of claiming social security for a mental health problem.

\section{Need for Support}

The forms for claiming disability benefits were commonly described as being complicated and requiring knowledge of what to include.

I underestimated a lot of the things I can't do, and I think it shows when you don't know how to fill in the form, it shows. And I think that's what, how they manage to 
put a lot of people off benefits. They make them deliberately complicated, and all the questions are there to trip you up rather than help you. (Nehal, Group 1)

Therefore, during analysis, Need for Support was constructed as the work claimants need to perform to both access social security and try to cope with the distress experienced while claiming social security. This included the appeals process if a claimant is first denied access to the benefit. Claiming Universal Credit, ESA and PIP for a mental health problem were frequently described as confusing processes, with participants describing finding the right person or organisation as time-consuming. Finding the right expert with the required knowledge was, however, described as helpful for coping with the system.

I've went to [named welfare rights organisation] and that girl was very helpful. She is gonna go to the appeal with me. So, if anybody is in the position I was in, I would advise them to seek help with [named welfare rights organisation] before going to [the WCA] (Eli, Focus Group 1)

Support from family and friends, if available, was reported as important for claimants negotiating the benefits process. Family and friends had to provide financial support for some when their benefit had been stopped.

Some friends helped me out, family. Sometimes you can get isolated from family when you have a mental health problem... I have to get support. That type of support I looked for in somewhere like [local support organisation], but [named local support organisation] took me off their list because they had cutbacks and that was very good for groups and that sort of thing. (Micah, Focus Group 4)

\section{Experiences of Social Stigma}

Though closely linked with experiences of loneliness and isolation, the existing framework did not readily capture the social stigma experienced by claimants for being a claimant. There were frequent discussions on the experience of stigma and during the analysis, it became apparent that participants felt that beyond being rejected by others within their own community, society perceived them as less of a person for being on benefits. In the example below, a participant describes how negative portrayals in the media may lead to social stigma. 
They don't actually specify on your worst day who you are or how, how basically the media in general perceive benefit claimants... but I think there is a kinda perceived bias, not perceived bias, but it's a perceived notion that if you aren't working or if you aren't looking for a job and you are on benefits you are some kind, some kind of less of a person" Ash, Focus Group 1)

Claimants spoke about social stigma, reporting that this makes them feel as if they are not contributing to society because they do not have a paid job. In the example below, a participant who does voluntary work describes how this kind of societal contribution is not valued in the same way as paid work.

I am contributing, yeah, but see if you are contributing in a voluntary manner, it's never looked at. (Nehal, Focus Group 1)

Furthermore, participants argued that frequent one-sided media portrayals reinforce doubts regarding the genuineness of individuals who claim benefits. This participant highlights an example in which the press will write reports about a small percentage of dishonest claimants, having the effect of making life difficult for genuine claimants.

The press with benefit scammers going on holiday, blah blah ... the wrong type of people have been claiming it, but they make it worse for the majority who are genuine. (Micah, Focus Group 4)

In some instances, participants mentioned the pronouncements of those in elected office which fail to acknowledge the disabling effects of mental health problems. This can have a significant impact upon the social stigma and discrimination experienced by people who claim benefits for mental health problems.

There was a government minister last month, said that he would prefer benefits for incapacity or disability were targeted at people which he called had real disabilities, not being who have mental health issues. (Lan, Focus Group 2)

\section{Suggestions for Improvement}


Throughout the focus groups, there was a perception that assessors perform social security medical assessments without an adequate understanding of the impact of mental health problems on claimants. One main suggestion for improving the process is for assessments to be conducted by individuals with appropriate training and proficiency in mental health care:

Even if you go for a workplace assessment or an appeal, there should be, surely there should be a mental health assessment [Nehal: That's what I think!] If you've got something from the heart, there would be a cardiologist there. It's someone, you obviously going to make sure it's objective who is there, and speak to the person (Jo, Focus Group 1)

Another suggestion for improvement is for the assessment to be more holistic and to consider the "whole picture" of a person's life. This should include reports from medical professionals to enhance key aspects of a person's day-to-day functioning. This may not be captured within the narrow confines of a one-off medical assessment or from the completion of a static form. In both examples below, claimants highlight the pitfalls of assessments not considering the broader context of a claimant's life.

They need to look at the whole picture... they need to be holistic and they are not, they are looking at one side, all they are looking at is how you have answered these questions and how this adds up...” (Bobbie, Focus Group 2)

You are actually assessed straight away on your cleanliness, on your appearance and it's down to if you are clean and the clothes that you wear are clean and the way it turned out, you are actually marked up for that. When you sit down, if you are clean shaven and if you hold eye contact, you are marked up for that as well. If you can have a conversation and a structured conversation, you are marked up for that as well... But what they don't actually, sorry, what they aren't taking into consideration is, if you've got a partner, husband, wife, whatever, and you get to that morning and they say "right, you need to go for a shower, you need to have a shave, you need to make yourself presentable"... they are just taking one snap judgement of you on that interview and make the basis of that. (Ash, Focus Group 1)

For existing claimants, the current system is characterised by reassessment forms being sent at seemingly random intervals, prompting attendance at a medical assessment and leading 
those to feel particularly precarious. Suggestions on how to improve this include giving plenty of advance notice if a reassessment is due, which was felt to be especially important as it gives people a chance to organise support to help fill out forms or attend medicals.

Should be able to get the form, maybe pre-warned, "your form is coming in this week," so all right, I gotta get something set up in place. And then get everything into place to get you support to fill these forms in rather than just frighten people later on. (Jo, Focus Group 1)

While support from other people and organisations was highly valued, some participants stated that the quality of the support offered could vary. Having standardised support provision can, therefore, be constructed as a recommendation from these focus groups. In particular, this participant states a preference for one overarching organisation to oversee the provision of welfare rights advice, which would allow for greater consistency.

"We have got all different people supporting you with making claims or with going to a tribunal to help you. There should be one organisation to have that flow of consistency. You can go to different people and they will tell you different things...." (Jo, Focus Group 1)

Claimants recommended that the system should be evaluated and researched in order to be improved. Throughout the focus groups, current claimants repeatedly expressed concern that at present, the system is driven by political motivations rather than the quality of service provision.

"I would like to see them host research and evaluation, to perfect the process, as you need to refine it as we go on, because too much... is driven, as you can imagine, by political and financial experience and that can get in the way, you know?" (Lan, Focus Group 2)

Linked in with Experiences of Social Stigma, participants recognised the need to tackle negative public attitudes towards people claiming benefits for mental health problems. Common suggestions from focus groups tended to be themed around providing education to the general public on why people need benefits for mental health problems and how mental health problems impact upon people more generally. 
"Would say with the likes of mental health it needs a little bit more education, I think. I am talking about general public information, that's where it is needed" (Pat, Focus Group 3).

Also in connection with Experiences of Social Stigma, participants suggested that negative media reporting of people claiming social security should be brought under control. As demonstrated below, a participant highlighted specific media outlets as a source of negativity, going as far as to suggest that banning them outright would improve the lives of social security claimants.

"Ban [named television channel] and possibly the [named tabloid newspaper]" (Rit, Focus Group 3).

\section{Discussion}

This study aimed to explore the validity of the austerity ailments conceptual framework (McGrath et al., 2015). In particular, the research examined the extent to which this existing framework captured the events of individuals experiencing mental health problems who are currently claiming benefits. The main finding was that themes generated from the focus groups provided evidence to support the validity of the austerity ailments framework in the specific case of claiming social security for a mental health problem in Glasgow. However, the framework did not fully capture claimant experiences, and two further themes (Social Stigma and Need for Support) were proposed.

The domain of Humiliation and Shame was strongly represented in participants' narratives, where shame and humiliation appear linked to a lack of agency within the social security system, reported in previous work (McNeill, Scullion, Jones, \& Stewart, 2017; Sage, 2018). Participants in this study spoke about their lack of agency in terms of being treated like a number, having to accept mistakes made by the benefits agency. This study suggested that many participants felt that society perceived them as not contributing appropriately, leading to shame, experiences of stigma and the need to lie about their situation in order to avoid social rejection or judgement. This appeared to directly affect participants' wellbeing and demonstrated common rhetoric used to describe the discourse of 'deservingness'. Findings consistent with the broader body of literature suggesting that austerity measures are 
associated with higher levels of distrust, shame and self-stigma as a direct consequence of negative rhetoric towards benefit claimants (Baumberg, Bell, \& Gaffney, 2012; Patrick, 2014).

The domain of Fear and Distrust was strongly supported within participants' narratives and was a crucial component in the negative impact of accessing social security. Having to prove their eligibility for disability benefits by completing complex forms and attending medicals left participants feeling anxious, frustrated and demoralised. Claimants frequently reported that their wellbeing was misrepresented by assessors, indicating an extreme distrust in the current system of assessments. This is comparable with findings from a recent United Nations report on the impact of austerity on disabled people in the UK (Alston, 2018). Furthermore, feelings of fear resulting from receiving forms in the post from the DWP were frequently mentioned in the present study. This theme is reflected in previous research (Garthwaite, 2014) which provides evidence of claimants experiencing fear and anxiety when receiving letters from the DWP, due to uncertainty and unrealistic deadlines. Claimants were afraid of losing entitlement to their benefits when transferring from DLA to PIP, a fear which appears well-founded (Pybus, Pickett, Prady, Lloyd, \& Wilkinson, 2019) because claimants with a mental health problem are more likely to lose their benefits than those claiming for physical health problems.

The study illustrated robust support for the domain of Isolation and Loneliness, which was prevalent in the experiences of participants and appeared to be interconnected with the theme of Instability and Insecurity. Participants increasingly felt unable to maintain friendships due to financial insecurity and feeling ashamed about their situation, all of which impacted on their wellbeing. Social isolation has been found to promote mental ill-health and presents a barrier to recovery while simultaneously increasing the risk of mortality (HoltLunstad et al., 2010). Financial insecurity and instability had a detrimental effect on the mental health of claimants, and therefore, policymakers should consider the psychosocial impact of austerity measures.

Being Trapped and Powerless was a relevant domain within narratives where participants expressed feeling trapped by the bureaucracy of the system, which had haltered aspects of their lives, leading claimants to feel as though they were spectators in society. Additionally, government cuts that have limited the support given by advocacy agencies 
appear to increase feelings of powerlessness. This is congruent with independent reviews showing that the reduction in government spending has adversely influenced the provision of welfare advice services at a time when demand for these services is increasing (Citizens Advice Bureau, 2014).

One key area not fully covered by the framework was the social stigma of being a benefits claimant. Participants in this study noted that disability benefits claimants are frequently subject to negative media portrayals, which is in line with the evidence of a report on the media coverage of disability in the UK. Research suggests that newspaper coverage about disabled people has become less sympathetic, with an increase in articles on disability benefits and fraud in 2010 and 2011 compared with 2004 and 2005 (Briant, Watson, \& Philo, 2013). Negative media representations of disabled and long-term sick individuals have been linked to rising levels of hostility and a 50 percent increase in disability hate crimes between 2009 and 2011 (Beresford, 2016; McWade, 2014). A recent summary (Mills, 2018) states that newspaper and television news portrayal of claimants embed a new form of commonsense that garners public disgust towards 'skiver' claimants, which entrenches public consent for welfare reform.

Participants in these focus groups made explicit links between the use of derogatory language in the media and the ways in which political leaders speak about disabled people as being undeserving of benefits. Claimants reported that their contributions to society, such as through voluntary work, are overlooked if they do not have paid work. Narratives from the present study highlight that our participants felt exposed to negative discourses discrediting the genuineness of those who are claiming benefits for mental health problems. Interviews revealed participants believe that the language used when discussing disability benefit claimants has important implications for how they are treated within society. Similar to research that has been conducted on claimants for physical disability (Saffer, Nolte, \& Duffy, 2018), our results foreground the importance of stigmatised identity. Social stigma is, by its nature, externally imposed. Therefore, the findings of this study support concern expressed in other work that the distress experienced by claimants has been overly medicalised, which obscures social antecedents (Thomas et al., 2018). Claimants in these focus groups described having a stigmatised identity, which is externally imposed on them. Such institutional stigma against people who claim benefits for a mental health problem has been reported in other 
research (Huggett et al., 2018) and without a change in societal attitudes, claimants are highly unlikely to escape from negative experiences associated with social stigma.

Need for Support was identified as a further crucial theme. The results of this study suggest that formal support is often required when engaging with the social security system. Finding an organisation to help claim benefits formally was highlighted as an important source of support, but finding such support could be difficult, as participants reported that many organisations in this area had had their funding cut. Concerns that cuts, to support services, have left vulnerable people to attempt to navigate the complex benefits system alone have been highlighted in the findings of a report from a visiting member of the United Nations (Alston, 2018).

\section{Improvement Recommendations}

A recommendation for improvement, made by participants, was the suggestion to enrol all assessors and advisors in mental health training courses so that they understand mental health difficulties more fully. However, the effectiveness of mental health educationbased interventions for changing attitudes and behaviours towards people with mental health problems is inconsistent. Some studies suggest that educational interventions may increase knowledge of common mental health disorders, but changes were short-term and did not lead to participants treating individuals with mental health problems more empathically (Corrigan, 2012; Jensen, Morthorst, Vendsborg, Hjorthøj, \& Nordentoft, 2016). Therefore, this recommendation should be interpreted under caution in light of the literature.

Claimants state that they would value an end to random reassessments in improving the system. While PIP award notices state claimants will be paid money until a particular date before being reassessed, in reality, they can be reassessed at any time. ESA award letters are not for a specified period, which means the claimant is unaware if and when they will be reassessed. The fear described by participants in these focus groups about a surprise 'brown envelope' form arriving through the letter box summoning them for a reassessment is in line with earlier work (Garthwaite, 2014). Reoccurring narratives from our study indicate that participants spend weeks at a time worrying about receiving forms from the DWP, leading to a drop in their mental wellbeing. When a 'brown envelope' arrives, claimants have four weeks to fill out and return the form, and while extensions can be requested, it is not 
guaranteed that they will be granted. Participants noted that receiving a notification before the arrival of each letter would allow them to plan for adequate support and removes the element of uncertainty, and additionally, claimants would value being promptly informed about decisions to reduce the distress associated with uncertainty.

Participants reported inconsistency in advice when speaking to advisors. One Scottish study suggests that providing welfare rights advice services in-house, within primary health care, may have a positive impact on people's physical and mental wellbeing and lead to an overall reduction in NHS costs (Sinclair, 2017). Therefore, it may be of benefit to provide inhouse welfare rights support within easy to reach services, such as general practice. Mental health staff were identified as key sources of support in claiming, because they can provide medical evidence. Therefore, highlighting the importance of this task to mental health professionals and providing information how they can practically help (including in the appeals process) appears to be important - see Galloway (Galloway, Boland, \& Williams, 2018) for an example.

Universal Credit (a newer benefit replacing ESA and housing benefit) was associated with particular concerns. Universal Credit is paid monthly, causing participants to expect that this will lead to problems with budgeting, especially for people with mental health problems associated with impulsive spending, such as bipolar (Richardson, Jansen, \& Fitch, 2018). At the time of writing, the implementation of Universal Credit has been associated with increased robberies (Scottish Police Authority, 2018) and suicide (Cheetham \& Moffatt, 2018), suggesting broader negative impacts. Considering the concern raised by participants within the current study and these other findings, we argue Universal Credit needs to be urgently re-designed or scrapped.

While participants recommended that educating the public might help reduce social stigma against benefit claimants, there is a risk that anti-stigma campaigns can overemphasise individualistic accounts of distress (Friedli, 2016). Overemphasising an individualistic focus on distress may result in systematic neglect of the impact of structural issues such as the benefits system. Finally, while participants gave many improvement suggestions and wanted these to be compiled, it is essential to note that evidence selection within the DWP appears constrained by austerity ideology (Monaghan \& Ingold, 2019). 


\section{Limitations and Future Research}

This study contributes to the literature as a piece of participatory social welfare research developed with the direct inclusion of claimants and their carers from the design stage until analysis and writing up. However, the findings should be considered within their limitations as this study was restricted to one urban region in Scotland; therefore, findings may not be representative of those across the country, particularly those in more rural areas. For example, the introduction of Universal Credit, which requires internet access to claim, has been raised as a particular concern for those in rural areas, where internet provision or access to libraries may be poorer (Black, Scott, \& Shucksmith, 2018).

The study was completed during a period of benefits system flux within the UK, with many changes and new benefits such as Universal Credit being implemented. Therefore, claimants discussed many different incapacity benefits during the focus groups, and while this may be considered a limitation within qualitative research because of a lack of homogeneity, claimants were quite clear that the benefit changes were a source of fear and alarm. Furthermore, the theme of Social Stigma was not limited to any particular incapacity benefit, but a general experience associated with claiming social security for a mental health problem.

All coders agreed that the Austerity Ailments framework did not fully capture people's lived experience and constructed some additional themes. However, while we did reach a consensus for final themes to include in this report, we did not always agree on the extent to which aspects of the framework were apparent in participant narratives. For example, during group coding, the coder with personal experience reported that the domain of being trapped and powerless was more apparent within participant discussions than the other two coders, who did not disclose personal experience. We argue that in attempting coproductive research, we should be open to the fact that people with differing experiences of oppression may interpret things differently. Those with extensive academic training are not necessarily always more "correct" in their interpretations of qualitative data. We believe this is particularly important because research outputs may inform policy which impacts upon social security claimants. Therefore, those who directly experience policies have a right to be part of any research exploring their impact. Strategies such as asking participants to check the 
analysis of their data for accuracy (Doyle, 2007) were not utilised and would likely have improved this study.

All participants in these focus group members belonged to peer-run support groups, and the findings of the study should be interpreted in light of this. We may have missed important insights from claimants who are not a part of existing support groups and suggest that this is an important group of people to involve in future participatory social welfare research. A further limitation is that this study only focused on experiences of the process of claiming benefits, meaning that other important aspects of welfare conditionality that impact upon claimants, such as benefit sanctions, (Adler, 2018; Fletcher \& Wright, 2018) were overlooked.

\section{Implications}

The findings of this research align with others who state (Saffer et al., 2018) that the current process of claiming benefits for a health problem within the UK requires urgent improvement. The Mental Health Strategy for Scotland states that Scotland should be a place in which people can get the right help at the right time, expect recovery and be free from discrimination and stigma (Scottish Government, 2017). Connectedness (having good relationships), Hope (having hope that recovery is possible and support to achieve this), Identity (having a positive sense of self), Meaning (living a purposeful life) and Empowerment (having control over life) (CHIME) is proposed as a framework of what is necessary for a person to experience recovery in terms of their mental health (Leamy, Bird, Le Boutillier, Williams, \& Slade, 2011). While the very concept of recovery in the context of mental health is highly contested (see (Harper \& Speed, 2013)), and can be described as having been co-opted by policymakers (Recovery in the Bin, 2019), we draw upon it within this discussion because policy in Scotland (Scottish Government, 2017) states that people with mental health problems should expect recovery and to be free from stigma. These findings suggest that having to claim social security benefits for a mental health problem makes it difficult to achieve any aspect of recovery as defined by CHIME (Leamy et al., 2011). This is because the benefits system creates barriers to participation in society. Barriers to participating in society emerge from both the low financial level of benefits, and fear that 
even maintaining eye contact during social interaction with assessor could be taken as a sign that a claimant is not unwell enough to be deserving of welfare support.

CHIME has been critiqued (Stuart, Tansey, \& Quayle, 2017) for underestimating the difficulties that many people with mental health problems face, and also because recovery as a concept may obscure social detriments of mental health. People often interact with the social security system when they are experiencing difficulties such as losing a job or becoming disabled, life events which can be triggers for suicidal thoughts (The Scottish Government, 2018).Our findings suggest that being a benefits claimant can be difficult for people with a mental health problem and its impact (including social stigma) upon mental health should not be underestimated.

\section{Conclusions}

The findings of this study demonstrate that people are suffering distress as a result of the process of claiming benefits for their mental health problems. Taken together, the results of this study provide support for the validity of the austerity ailments framework (McGrath et al., 2015). Results suggest that claiming benefits for a mental health problem is currently humiliating, isolating and frightening for claimants, making them feel that their lives are unstable in a way they feel powerless to control. However, the findings suggest that it is overly reductionist to attempt to understand the experiences of accessing social security from a purely psychological perspective, for example, social stigma was constructed as a distinctly non-individual problem. This study makes a contribution as a piece of participatory social welfare research and provides suggestions of how to improve the system, which are empirically grounded in the needs of the claimants that the system is supposed to serve. 


\section{References}

Adler, M. (2018). The Historical Development of Benefit Sanctions in the UK BT - Cruel, Inhuman or Degrading Treatment? Benefit Sanctions in the UK (M. Adler, ed.). https://doi.org/10.1007/978-3-319-90356-9_3

Alston, P. (2018). Statement on Visit to the United Kingdom, by Professor Philip Alston, United Nations Special Rapporteur on extreme poverty and human rights.

Barr, B., Taylor-Robinson, D., Stuckler, D., Loopstra, R., Reeves, A., \& Whitehead, M. (2016). 'First, do no harm': Are disability assessments associated with adverse trends in mental health? A longitudinal ecological study. Journal of Epidemiology and Community Health, 70(4), 339-345. https://doi.org/10.1136/jech-2015-206209

Baumberg, B. (2014). Fit-for-work - Or work fit for disabled people? the role of changing job demands and control in incapacity claims. Journal of Social Policy, 43(2), 289-310. https://doi.org/10.1017/S0047279413000810

Baumberg, B., Bell, K., \& Gaffney, D. (2012). Benefits Stigma in Britain. 96. https://doi.org/10.1103/PhysRevB.66.113105

Baumberg, B., Warren, J., Garthwaite, K., \& Bambra, C. (2015). Rethinking the Work Capability Assessment. https://doi.org/http://dx.doi.org/10.1037/xge0000076

Beatty, C., Fothergill, S., \& Houston, D. (2013). The impact of the UK's disability benefit reforms. In C. Lindsay \& D. Houston (Eds.), Disability Benefits, Welfare Reform and Employment Policy (pp. 134-152). London: Palgrave Macmillan.

Belone, L., Lucero, J. E., Duran, B., Tafoya, G., Baker, E. A., Chan, D., ... Wallerstein, N. (2016). Community-Based Participatory Research Conceptual Model: Community Partner Consultation and Face Validity. Qualitative Health Research, 26(1), 117-135. https://doi.org/10.1177/1049732314557084

Beresford, P. (2016). Presenting welfare reform: poverty porn, telling sad stories or achieving change? Disability and Society, 31(3), 421-425. https://doi.org/10.1080/09687599.2016.1173419

Beresford, P., \& Carr, S. (2018). Social Policy First Hand. London: Policy Press.

Black, N., Scott, K., \& Shucksmith, M. (2018). Social inequalities in rural England: Impacts on young people post-2008. Journal of Rural Studies, (September), 1-12. https://doi.org/10.1016/j.jrurstud.2018.09.008

Briant, E., Watson, N., \& Philo, G. (2013). Reporting disability in the age of austerity: the changing face of media representation of disability and disabled people in the United Kingdom and the creation of new 'folk devils'. Disability and Society, 28(6), 874-889. 
https://doi.org/10.1080/09687599.2013.813837

Brooks, J., McCluskey, S., Turley, E., \& King, N. (2015). The Utility of Template Analysis in Qualitative Psychology Research. Qualitative Research in Psychology, 12(2), 202222. https://doi.org/10.1080/14780887.2014.955224

Cheetham, M., \& Moffatt, S. (2018). “It's hitting people that can least afford it the hardest " the impact of the roll out of Universal Credit in two North East England localities : a qualitative study. 1-47.

Citizens Advice Bureau. (2014). Submission to the 5th Independent Review of the Work Capability Assessment Citizens Advice. (August).

Clark, M. (2015). Co-production in mental health care. Mental Health Review Journal, 20(4), 213-219. https://doi.org/10.1108/MHRJ-10-2015-0030

Cooper, K., \& Stewart, K. (2015). Does money in adulthood affect adult outcomes? Joseph Rowntree Foundation, (January 2015).

Corrigan, P. W. (2012). Where Is the Evidence Supporting Public Service Announcements to Eliminate Mental Illness Stigma? Psychiatric Services, 63(1), 79-82. https://doi.org/10.1176/appi.ps.201100460

Cummins, I. (2018). The impact of austerity on mental health service provision: A UK perspective. International Journal of Environmental Research and Public Health, 15(6). https://doi.org/10.3390/ijerph15061145

de Wolfe, P. (2012). Reaping the benefits of sickness? Long-term illness and the experience of welfare claims. Disability and Society, 27(5), 617-630. https://doi.org/10.1080/09687599.2012.669107

Doyle, S. (2007). Health Care for Women International Member Checking With Older Women : A Framework for Negotiating Meaning Member Checking With Older Women : A Framework for Negotiating Meaning. (November 2014), 37-41. https://doi.org/10.1080/07399330701615325

Fletcher, D. R., \& Wright, S. (2018). A hand up or a slap down? Criminalising benefit claimants in Britain via strategies of surveillance, sanctions and deterrence. Critical Social Policy, 38(2), 323-344. https://doi.org/10.1177/0261018317726622

Friedli, L. (2016). The politics of tackling inequalities: The rise of psychological fundamentalism in public health and welfare reform. In K. Smith, S. Hill, \& C. Bambara (Eds.), Health inequalities: critical perspectives. Oxford University Press.

Gale, N. K., Heath, G., Cameron, E., Rashid, S., \& Redwood, S. (2013). Using the framework method for the analysis of qualitative data in multi-disciplinary health 
research. BMC Medical Research Methodology, 13(1), 1. https://doi.org/10.1186/14712288-13-117

Galloway, A., Boland, B., \& Williams, G. (2018). Mental health problems, benefits and tackling discrimination. BJPsych Bulletin, 42(5), 200-205.

https://doi.org/10.1192/bjb.2018.43

Garthwaite, K. (2014). Fear of the brown envelope: Exploring welfare reform with long-term sickness benefits recipients. Social Policy and Administration, 48(7), 782-798. https://doi.org/10.1111/spol.12049

Griffiths, T., \& Patterson, T. (2014). Work Capability Assessment concerns. Journal of Poverty and Social Justice, 22(May 2014), 59-70. https://doi.org/10.1590/S004296862004001000005

Grover, C., \& Piggott, L. (2013). Employment and Support Allowance: Capability, personalization and disabled people in the UK. Scandinavian Journal of Disability Research, 15(2), 170-184. https://doi.org/10.1080/15017419.2012.686890

Harper, D., \& Speed, E. (2013). Uncovering recovery: The resistible rise of recovery and resilience. Studies in Social Justice, 6(1), 9-26.

Harrington, M. (2012). An Independent Review of the Work Capability Assessment - year three. Retrieved from http://www.colchesterhospitalpug.co.uk/work-capabilityassessment-year-4-paul-litchfield.pdf\%5Cnpapers2://publication/uuid/2747B433-BEA74A61-8A3A-B8C64C646F2A

Hastings, A., Bailey, N., Besemer, K., Bramley, G., Gannon, M., \& Watkins, D. (2013). Coping with the cuts? Local government and poorer communities. Joseph Rowntree Foundation Programme Paper, (November), 1-59.

Holt-Lunstad, J., Smith, T. B., \& Layton, J. B. (2010). Social relationships and mortality risk: A meta-analytic review. PLoS Medicine, 7(7). https://doi.org/10.1371/journal.pmed.1000316

Huggett, C., Birtel, M. D., Awenat, Y. F., Fleming, P., Wilkes, S., Williams, S., \& Haddock, G. (2018). A qualitative study: experiences of stigma by people with mental health problems. Psychology and Psychotherapy: Theory, Research and Practice, 91(3), 380397. https://doi.org/10.1111/papt.12167

Jensen, K. B., Morthorst, B. R., Vendsborg, P. B., Hjorthøj, C., \& Nordentoft, M. (2016). Effectiveness of Mental Health First Aid training in Denmark: a randomized trial in waitlist design. Social Psychiatry and Psychiatric Epidemiology, 51(4), 597-606. https://doi.org/10.1007/s00127-016-1176-9 
Kim, S., Thibodeau, R., \& Jorgensen, R. S. (2011). Shame, Guilt, and Depressive Symptoms: A Meta-Analytic Review. Psychological Bulletin, 137(1), 68-96. https://doi.org/10.1037/a0021466

Leamy, M., Bird, V., Le Boutillier, C., Williams, J., \& Slade, M. (2011). Conceptual framework for personal recovery in mental health: Systematic review and narrative synthesis. British Journal of Psychiatry, 199(6), 445-452. https://doi.org/10.1192/bjp.bp.110.083733

Litchfield, P. (2013). An Independent Review of the Work Capability Assessment-year four. Retrieved from http://www.colchesterhospitalpug.co.uk/work-capability-assessmentyear-4-paul-litchfield.pdf\%5Cnpapers2://publication/uuid/2747B433-BEA7-4A618A3A-B8C64C646F2A

Machin, R. (2017). Made to measure? An analysis of the transition from Disability Living Allowance to Personal Independence Payment. Journal of Social Welfare and Family Law, 39(4), 435-453. https://doi.org/10.1080/09649069.2017.1390291

MacLeod, M. A., Curl, A., \& Kearns, A. (2019). Understanding the prevalence and drivers of food bank use: Evidence from deprived communities in Glasgow. Social Policy and Society, 18(1), 67-86. https://doi.org/10.1017/S1474746418000064

McGrath, L., Griffin, V., \& Mundy, E. (2015). The Psychological Impact of Austerity. Psychologists Against Austerity, 1-16. https://doi.org/10.1080/09540129008257758

McNeill, J., Scullion, L., Jones, K., \& Stewart, A. (2017). Welfare conditionality and disabled people in the UK: Claimants' perspectives. Journal of Poverty and Social Justice, 25(2), 177-180. https://doi.org/10.1332/175982717X14943392083755

McWade, B. (2014). Real lives on the wall: disabled people use public murals to convey the reality of their lives in the UK. Disability \& Society, 29(7), 1166-1167. https://doi.org/10.1080/09687599.2014.919173

Mills, C. (2018). 'Dead people don't claim': A psychopolitical autopsy of UK austerity suicides. Critical Social Policy, 38(2), 302-322. https://doi.org/10.1177/0261018317726263

Monaghan, M., \& Ingold, J. (2019). Policy Practitioners' Accounts of Evidence-Based Policy Making: The Case of Universal Credit. Journal of Social Policy, 48(2), 351-368. https://doi.org/10.1017/s004727941800051x

Patrick, R. (2014). Working on welfare: Findings from a qualitative longitudinal study into the lived experiences of welfare reform in the UK. Journal of Social Policy, 43(4), 705725. https://doi.org/10.1017/S0047279414000294 
Pybus, K., Pickett, K. E., Prady, S. L., Lloyd, C., \& Wilkinson, R. (2019). Discrediting experiences: outcomes of eligibility assessments for claimants with psychiatric compared with non-psychiatric conditions transferring to personal independence payments in England. BJPsych Open, 5(2), 1-5. https://doi.org/10.1192/bjo.2019.3

Recovery in the Bin. (2019). 10 Key Principles of Recovery In The Bin.

Richardson, T., Jansen, M., \& Fitch, C. (2018). Financial difficulties in bipolar disorder part 1: longitudinal relationships with mental health. Journal of Mental Health (Abingdon, England), O(0), 1-7. https://doi.org/10.1080/09638237.2018.1521920

Saffer, J., Nolte, L., \& Duffy, S. (2018). Living on a knife edge: the responses of people with physical health conditions to changes in disability benefits. Disability \& Society, $O(0)$, 1-24. https://doi.org/10.1080/09687599.2018.1514292

Sage, D. (2018). Reversing the Negative Experience of Unemployment: A Mediating Role for Social Policies? Social Policy and Administration, 52(5), 1043-1059. https://doi.org/10.1111/spol.12333

Samuel, K., Alkire, S., Zavaleta, D., Mills, C., \& Hammock, J. (2018). Social isolation and its relationship to multidimensional poverty. Oxford Development Studies, 46(1), 83-97. https://doi.org/10.1080/13600818.2017.1311852

Scottish Government. (2017). Mental Health Strategy: 2017-2027. Mental Health Strategy, 2017-2027. Retrieved from http://www.gov.scot/Resource/0051/00516047.pdf

Scottish Police Authority. (2018). Police Scotland Performance Report July-September 2018.

Sinclair, J. (2017). The Deep End Advice Worker Project: embedding an advice worker in general practice settings EXECUTIVE SUMMARY. (September).

Staniszewska, S., Brett, J., Simera, I., Seers, K., Mockford, C., Goodlad, S., ... Tysall, C. (2017). GRIPP2 reporting checklists: Tools to improve reporting of patient and public involvement in research. BMJ (Online), 358. https://doi.org/10.1136/bmj.j3453

Stuart, S. R., Tansey, L., \& Quayle, E. (2017). What we talk about when we talk about recovery: a systematic review and best-fit framework synthesis of qualitative literature. Journal of Mental Health, 26(3), 291-304. https://doi.org/10.1080/09638237.2016.1222056

The Scottish Government. (2018). Every life matters : Scotland's Suicide Prevention Action Plan. 22. Retrieved from https://www.gov.scot/Publications/2018/08/8874

Thomas, F., Hansford, L., Ford, J., Wyatt, K., McCabe, R., \& Byng, R. (2018). Moral Narratives and Mental Health: Rethinking Understandings of Distress and Healthcare 
Support in Contexts of Austerity and Welfare Reform. Ssrn, (2018).

https://doi.org/10.1057/s41599-018-0091-y

Tong, A., Sainsbury, P., \& Craig, J. (2007). Consolidated criterio for reporting qualitative research (COREQ): a 32- item checklist for interviews and focus group. International Journal of Qualitative in Health Care, 19(6), 349-357.

https://doi.org/10.1093/intqhc/mzm042

Viola, S., \& Moncrieff, J. (2016). Claims for sickness and disability benefits owing to mental disorders in the UK: trends from 1995 to 2014. BJPsych Open, 2(1), 18-24. https://doi.org/10.1192/bjpo.bp.115.002246

Zlotowitz, S., \& Williams, G. (2013). Using a Community Psychology Approach in Your Research. PsyPAG Quarterly, 86(86), 21-25. https://doi.org/10.1017/CBO9781107415324.004 